\title{
Study on Man-machine Design of Armoured Vehicles Operation Space
}

\author{
Du Hemin ${ }^{a}$, Wang Ting \\ Xi'an Technological University, Xi'an, Shaanxi 710021
}

\begin{abstract}
This paper proposes an improved armoured vehicle control room based on ergonomic theory and computer-aided design technology to create efficiency by improving panel layout and seat design. Current design of existing control rooms that do not maximize ergonomics can create operator fatigue and user error. Optimal control room design was created by considering console size, console layout, and user seat dimensions and were entered into JACK software for simulation tests.
\end{abstract}

\section{Analysis of interior design of armored vehicle control room}

\subsection{Control Room Design Factors}

Because the design of the armoured vehicle requires two operators in a limited space, it is critical to design the work area to maximize efficiency, personnel comfort so that the two operators can do their jobs without any impediments to their movements.

The design of the user's console is particularly critical because this space is limited where both of the operators will spend most of their time performing duties.

In response to both operators working long hours in the armoured vehicle performing duties, the console and control panel design in addition to the location of visual displays must be created so that the operators can quickly process information and respond to it while remaining physically comfortable at the same time.

\subsection{Manipulator Design Requirements}

The purpose of the control room is to observe data and use instruments on the console and visual displays. Console room design can be broken up into three elements: interior structural design, console layout and size, and seating design. All three elements are indispensable and should be considered equally in order to create the most efficient work space in the armoured vehicle.

The ergonomic variables to optimally design the control room are: The instruments and consoles should be within the operators' visual range and require little movement during operation, maximize quick and correct interpretation of the data, and minimize operators' movements and communication in response to the data.

\section{Armored car control room design}

* Corresponding author: ${ }^{a}$ author@e-mail.org principles

\subsection{Visual Domain Design Principles}

The range of vision of the seated operator can be divided into four viewing zones according to the speed of recognition of the visual signals by the human eye while the head remains still. The viewing zones include the central viewing zone, the best viewing zone and the effective viewing zone. The optimal design of the control panel should completely fall into the best and effective views.

The range for the best viewing zone is $15^{\circ}$ and $20^{\circ}$ horizontal in the direction of the plumb bob. The recognition effect of the best range allows the operator to recognize the data quickly and effectively. The range of effective viewing zones is $10^{\circ}$ between to $30^{\circ}$ in the direction of the plumb bob, and $30^{\circ}$ in the horizontal direction. The recognition effect of this range is that the operator needs to concentrate and take more time to recognize the data than the best viewing range

\subsection{Panel layout and colour design and design principles}

The location of buttons and joysticks on the control panel should be coordinated and prioritized based on operational sequence, importance or frequency of use. In the case where there are many buttons, the arrangement should be consistent with their function and should remain in the operator's best vision range.

Alert mechanisms should be designed to immediately catch the operator's attention so that the operator can identify and react to the threat in a timely and effective manner.

The colour of the buttons on the operation panel should be classified according to the purpose. For example, red indicates danger, Stop, prohibit, Green indicates safety, normal operation, and so on. In addition, 
the symbols, such as the code numbers used to indicate the functions, are located above or on the sides of the manipulation buttons or joysticks, and white and black are suitable.

\subsection{Seat design principles}

Ergonomic variables that go into the seat design are appropriate materials and the shape of the seat should conform to the contours of the human body. In addition, various seat designs should take into account the physiological needs of the human body that creates a reasonable spatial distance from the control console.

\subsubsection{Seat height analysis}

The height of the seat surface refers to the vertical distance between the horizontal surface of the seat to the ground. The height of the seat surface should make the position of the thighs line up with the seat horizontal and be parallel to the ground. The lower leg should remain naturally vertical and the soles of the feet should rest comfortably on the ground, ensuring that the lower body is comfortable and relaxed while the operator is performing tasks. Reducing back Muscle pressure can also be accomplished by making sure, so the chair is not too low to the ground for the operator.

\subsubsection{Seat width analysis}

The width of the seat surface of the chair is often narrower in front and wider than the width of the seat. The width of the front edge of the seat is wide before sitting, and the width of the back edge is wide after sitting. The width of the seat should allow the hips to be fully supported and have adequate room for movement to facilitate the sitting position of the seated person. In general, the width of the seat surface should be wide enough for the operator to comfortably execute a wide variety motions in performing tasks.

\subsubsection{Seat depth analysis}

The seat depth mainly refers to the distance from the leading edge to the trailing edge of the chair surface. The depth of the seat surface has a great effect on the sitting posture of the human body. Seat depth should meet three conditions: sufficient support for the buttocks; proper support of the back by the backrest; proper distance between the front edge of the seat and the lower leg to ensure the thigh The muscles are not pressured and the legs are free to move.

Therefore, the chair seat surface depth must be moderate in a seat design. If the chair surface is too deep and exceeds the horizontal length of the thigh, the backrest will cause the position of the back to have a large inclination, causing muscle fatigue in the lower back and thighs. In addition, if the depth of the seat surface is too shallow, a numbness of the leg or knee can result.

\subsubsection{Seat lumbar support and inclination analysis}

The waist of the seat should fit the waist of the human body perfectly and give the human body good support. It can effectively relieve the fatigue of the waist caused by sitting down for long periods of time. The lumbar support has no pressure point on the human body, which has a positive effect on the lumbar pain.

\section{3 armored vehicle control room design basis}

\subsection{Console width}

As the armoured vehicle control room is subject to space constraints, and the operator is mostly male, the size of the male encompasses $95 \%$ of all sizes men and is selected as the numerical basis for the console design.

The overall size of armoured vehicle control room space is: $1482 * 1427 * 1320(\mathrm{~mm})$, and two operator control consoles and access doors are also required. The maximum shoulder width of $95 \%$ of men in the horizontal dimension of the human body is $469 \mathrm{~mm}$. Sitting width of elbow and shoulder: $489 \mathrm{~mm}$, plus or minus $8 \mathrm{~mm}$. Based on the above values and combined with the space size and layout design, the widths of the No. 1 operator station and the No. 2 operator station are all calculated to be $489+8 * 2=505(\mathrm{~mm})$.

\subsection{Control console and display device height}

\subsubsection{Console height}

The height of the control console and display equipment in the control room must conform to two variables: the height limitation of the overall space and the height of operator to maximize comfort and range of motion in the limited space.

The measurement of $95 \%$ male males knee height while sitting was selected: $532 \mathrm{~mm}$ with an error of 25 $38 \mathrm{~mm}$. therefore, the height of the console was determined as: $532+38=570(\mathrm{~mm})$.

\subsubsection{Display device height}

The operator of the armoured vehicle needs to use two display devices at the same time to complete tasks. Due to the limited space of the control room, the layout of the display devices is set to the up and down layout mode, and the display device uses the 19-inch display.

19-inch screen size is: $376.8 * 301.4 \mathrm{~mm}$, the main display height is: $301.4 \mathrm{~mm} * \cos 10^{\circ}=296.8 \mathrm{~mm}$, the secondary display height: $301.4 * \cos 20^{\circ}=282.8 \mathrm{~mm}$ (Figure 1) Shown), the sum of the two results in a total height of $579.6 \mathrm{~mm}$ for both screens.

According to the height of the console and the height of the display device, the total height of the console is: $579.6+570=1149.6(\mathrm{~mm})$. 


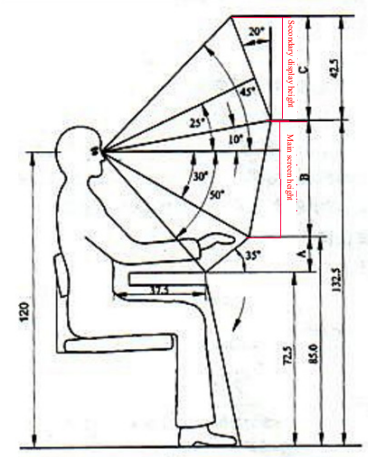

Figure 1. Screen size

\subsection{Console seat size}

\subsubsection{Seat height}

The mean length of the $95 \%$ male leg is: $403 \mathrm{~mm}$. This value of $403 \mathrm{~mm}$ is. The adjustment of the range of activity and comfortable position of the body parts. The comfort range of the calf to the thigh falls between $95^{\circ}$ and $120^{\circ}$. This value is assigned to the variable $\alpha$. As shown in Figure 2, we will finally get the seat height $h$. The calculation process is as follows:

Because, $\beta=5^{\circ}, \alpha \in\left(-95^{\circ} \sim-120^{\circ}\right)$, So, $\Omega \in$ $\left(-10^{\circ} \sim-35^{\circ}\right)$

$\beta=5^{\circ}, \alpha \in\left(-95^{\circ} \sim-120^{\circ}\right)$, therefore, $\Omega \in$ ($10^{\circ} \sim-35^{\circ}$ )

$\mathrm{L} 1=403, \Omega \in\left(-10^{\circ} \sim-35^{\circ}\right)$ this results in, h1 $\in$ (396.88 - -330.12mm)

$\mathrm{L} 1=403, \Omega \in\left(-10^{\circ} \sim-35^{\circ}\right)$, therefore, h1 $\in$ (396.88 -330.12mm)

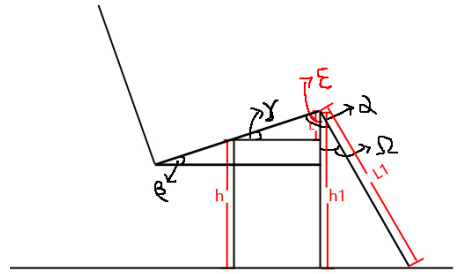

Figure 2. Seat height calculation example

It is known that $\gamma=\beta=5^{\circ}$ and it follows that $\varepsilon=85^{\circ}$. The seat depth in the main parameters of the work seat ranges from 360 to $390 \mathrm{~mm}$. Finally, the value range of $\mathrm{L}$ is 17.06 to $15.75 \mathrm{~mm}$. The seat height range calculation process is:

$396.88-17.06=379.82 ; \quad 330.12-17.06=313.06$

$396.88-15.75=381.13 ; \quad 330.12-15.75=314.37$

It can be concluded that the seat height of the armoured vehicle control room ranges from 313.06 to $381.13 \mathrm{~mm}$. In addition, if it is a step less adjustment seat, it is a file every $20 \mathrm{~mm}$.

\subsubsection{Seat width}

Male seated hip width $(284 \mathrm{~mm} \sim 369 \mathrm{~mm}), 95 \%$ of the male seat hip width correction value is: $13 \mathrm{~mm}$, obtained: seat width $\in(297 \mathrm{~mm} \sim 382 \mathrm{~mm})$
Because the seat width $(370 \mathrm{~mm}-420 \mathrm{~mm})$ is the main parameter of the seat, the width of the seat should not be too wide. The width of the shoulder should be the comfortable posture of the natural arm. Therefore, the seat width in the armoured vehicle should be: $395 \mathrm{~mm}$.

\subsubsection{Seat depth}

The main parameters of the work seat in the seat squat $(360 \mathrm{~mm} \sim 390 \mathrm{~mm})$, seat inclination $\in\left(0^{\circ} \sim 5^{\circ}\right)$, obtained, armoured vehicle seat depth calculation process for the seat range: $360 * \cos 5^{\circ}=31.5 \mathrm{~mm}$, $390^{*} \cos 5^{\circ}=34.12 \mathrm{~mm}$, seat depth $\in(31.5 \mathrm{~mm}$ $34.12 \mathrm{~mm})$.

\subsubsection{Seat lumbar support and inclination}

The main parameters of the work seat in the lumbar long range: $320 \sim 340 \mathrm{~mm}$, take the recommended value of $330 \mathrm{~mm}$;

Waist width range: $200 \sim 300 \mathrm{~mm}$, take the recommended value of $250 \mathrm{~mm}$;

Lumbar thickness range: $35 \sim 50 \mathrm{~mm}$, taking the recommended value of $40 \mathrm{~mm}$;

The height of lumbar support is: $165-210 \mathrm{~mm}$;

Waist radius of the arc is in the range of $400-700 \mathrm{~mm}$, taking the recommended value of $550 \mathrm{~mm}$;

The lumbar inclination angle ranges from $95^{\circ}$ to $115^{\circ}$ and the recommended value is $110^{\circ}$.

\section{Design and Simulation Analysis of Armored Vehicle Control Room}

\subsection{Design scheme}

Based on the data obtained from the above calculations on the dimensions of the control console, a control room model was established, shown in Figures 3, 4, and 5. Because the height of the operator has a certain variance, so the seat is adjustable (Figure 4) to account for the height difference between the operator and the height of the sitting position.

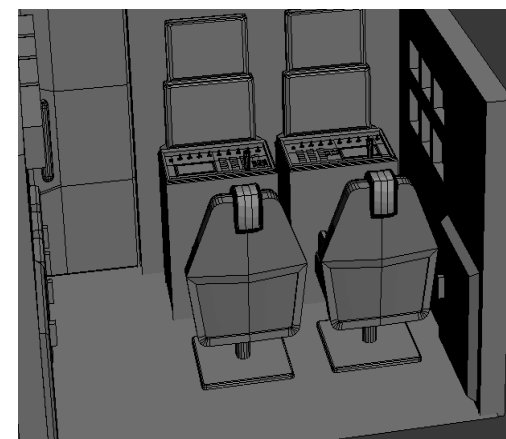

Figure 3. Manipulation room interior overall display 


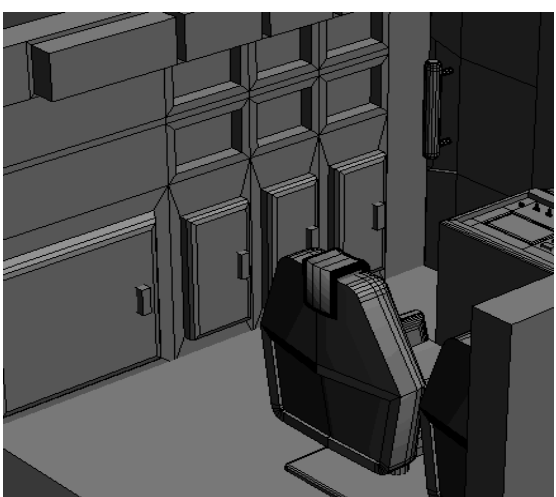

Figure 4. Control room left area display

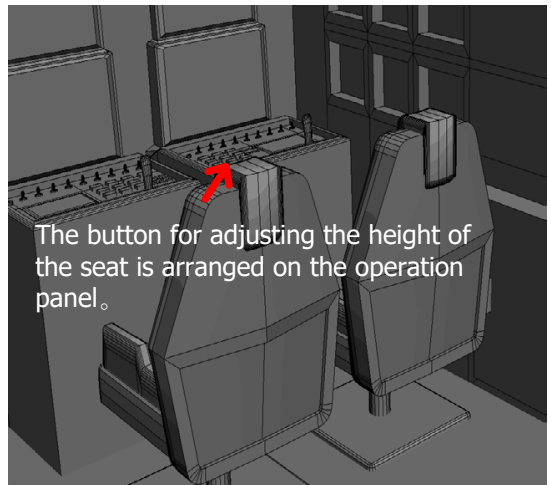

Figure 5. Manipulating indoor console display

\subsection{Human Machine Simulation}

\section{(1) Armoured Vehicle Operator Visual Field}

The visibility of the displays and control panels in the armoured vehicle control room must be considered. In order for the visual displays to be effective, they must be clearly seen by the operator. However, the speed and accuracy with which the armoured vehicle operator reacts to the display varies depending on the position of the display device in the operator's field of vision.

Figure 6 shows the visual field of the operator sitting on the left, where the purple area is the operator's righteye viewable area and yellow is the operator's left-eye viewable area. As shown in FIG. 6, the left operator's visual range can cover the operation panel and the display device it controls.

Figure 7 shows the visual field of the right operator, where the pink area is the operator's right eye viewable area and purple is the operator's left eye viewable area. As shown in the figure, the visual range of the right operator can also cover the operation panel and display device it controls.

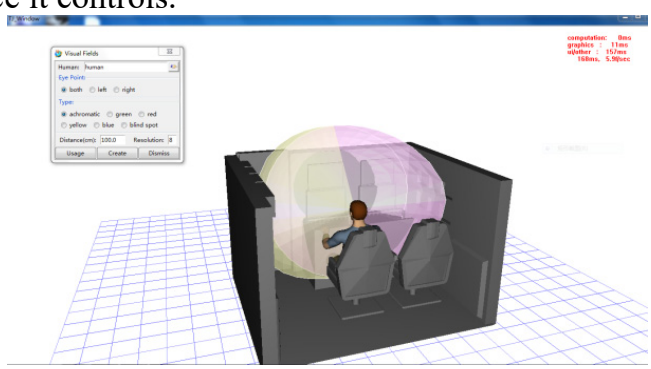

Figure 6. Left operator's visual field

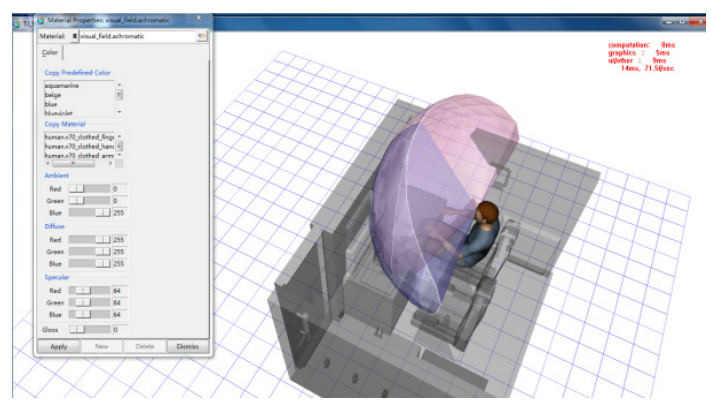

Figure 7. Right operator's visual field

Achievable accessibility of armoured vehicle operators

Figure 8 The coverage of the green area is the reachable domain of the left-hand operator's left hand. As shown in the figure, based on the above table, the operator's left-hand reachable domain is within reach.

Figure 9 The coverage area of the blue area is the reachable domain of the right operator's right hand. As shown in the figure, based on the above calculation data, the operator's right hand reachable domain is within reach.

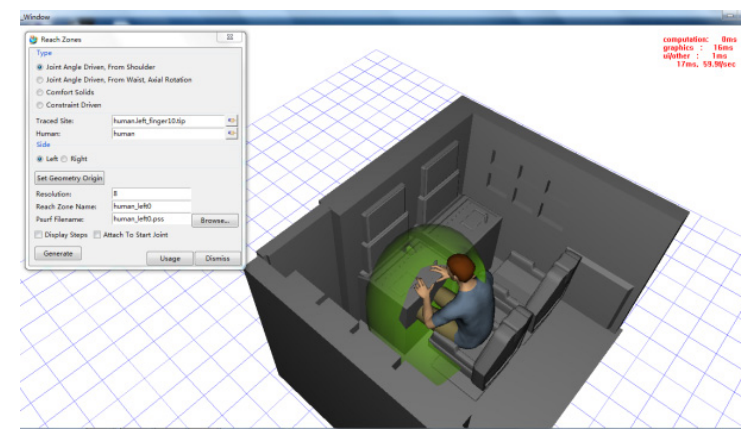

Figure 8. Left-hand reachable domain of left-hand operator

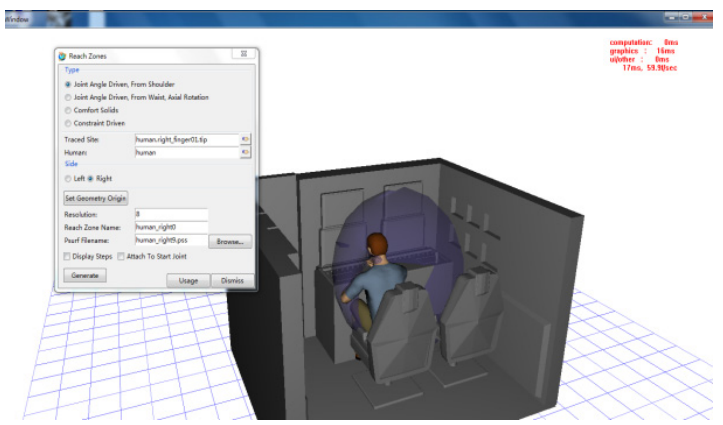

Figure 9. Right-hand reachable domain of left-hand operator

Figure 10 The coverage area of the red area is the reachable domain of the right-hand operator's left hand. As shown in the figure, the left-hand reachable domain of the right-hand operator is within the reachable range based on the above-mentioned measured data.

Figure 11. The coverage area of the red zone is the right-hand operator's right-hand reachable domain. As shown in the figure, the right-hand reachable domain of the right-hand operator is within the reach of the operator station based on the above measured data. 


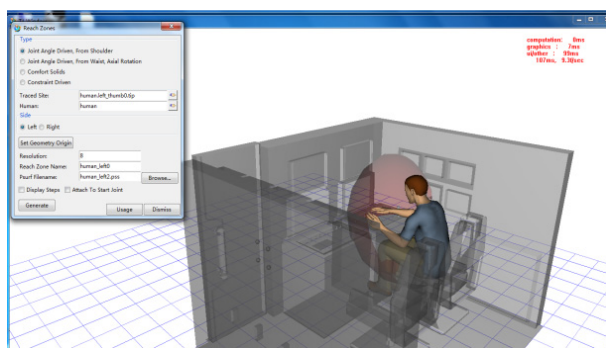

Figure 10. Left-hand reachable domain of the right operator

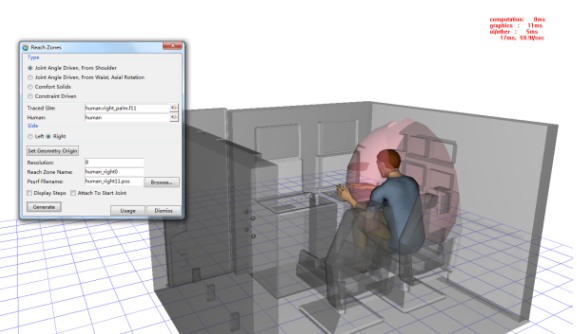

Figure 11. Right-hand reachable domain of the right operator

The comfort of armoured vehicle operators

In Figures 12 and 13, the High and Low values in the message box are the end points of the interval satisfying the operator's comfort requirements; the values shown by Value indicate the comfort calculated according to the position of a certain position; The numerical value indicates the theoretical optimum value of operator comfort in the same posture. When the Mode value goes to Low or High, comfort deteriorates.

Figure 12 shows the comfort level of the left-side operator. As shown in the figure, according to the abovementioned calculation data, the comfort level of the leftside operator during the normal operation is within the comfortable range.

Figure 13 shows the right operator's comfort test results. Due to the limited space of the control room, the comfort level of the left and right arms of the operator sitting on the right side is displayed in yellow, that is, the operator's right and left arm's comfort is only at the comfortable edge during normal operation.

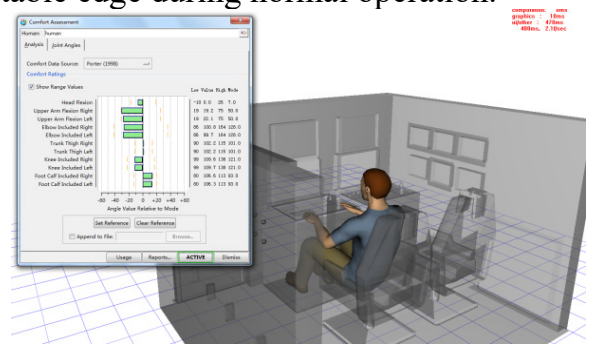

Figure 12. Left Operator Comfort

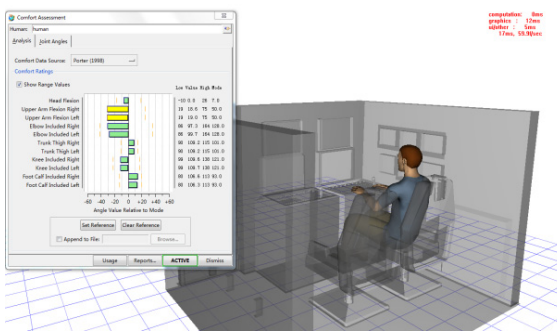

Figure 13. Right Operator Comfort

\section{Conclusion}

The control room inside the armoured vehicle is an organically interconnected microcosm of two separate components: the structure of the control room and the control platform. Included in the control platform component is the size and orientation of the control panel and ergonomic seat design. Based on objective data, the dimensions of the control console, the layout of the console panel, the colour of components on the console, and the dimensions of the seats on the control console were calculated to establish the model control room. In future designs of armoured vehicles an effort must be made to make the design and layout of the control room both comfortable and efficient for the operators.

Here are some examples:

\section{Reference}

1. Ding Yu-Lan. Ergonomics [M]. Beijing: Beijing institute of technology press, 2006.

2. Xiang Ying-Hua. Ergonomics [M]. Beijing: Beijing institute of technology press, 2008.

3. Tong Shi-Zhong. Man-machine engineering design and application manual [M]. Beijing: China standard press, 2007.

4. Ruan Bao-Xiang, Shao Xiang-Hua. Industrial design ergonomics [M]. Beijing: mechanical industry press, 2005.

5. Ma Zhi, Xue Hong-Jun, Su Run-E. Analysis of human body modeling and ergonomics based on JACK [J]. Aviation computing technology,2008, 38(1):97-100.

6. Dong Ai-Hua. Modelling and structural design of the console $[\mathrm{J}]$. Electronic mechanical engineering.2010, 3:21-23.

7. Song Xiao-Qing, Shen Xi. Research on control panel design based on ergonomics [J]. Equipment manufacturing technology.2006, 4: 67-69.

8. Li Le-Shan. Arts and design [M]. Xi 'an: xi 'an jiaotong university press, 2010 . 